\title{
Caso para ensino: Base comunitária de segurança da Vila Formosa, São Paulo (SP)
}

\author{
Bruno Martinelli ${ }^{1}$, Caio Siqueira Marconato ${ }^{1}, K$ Kayo Felype Nachtajler Amado
}

\author{
${ }^{1}$ Escola de Artes, Ciências e Humanidades da Universidade de São Paulo. \\ Correspondência: E-mail: bruno2.martinelli@usp.br \\ Av. Arlindo Béttio, 1000 \\ São Paulo - SP - Brasil \\ CEP 03828-000
}

Resumo Um caso para ensino é um relato de situações da vida organizacional, com o objetivo de desenvolver habilidades de resolução de problemas. Este estudo de caso para ensino é contado sob a ótica do Sargento Ciriaco, comandante da base. Desde 2007, a Base da Polícia Militar de Vila Formosa, localizada na zona leste do município de São Paulo, faz parte do programa de policiamento comunitário. Em agosto de 2008, no início da gestão do Sargento Ciriaco, foi adotada a filosofia da integração com a comunidade. Parcerias com a polícia comunitária do Japão, comerciantes locais, e outros órgãos do governo foram realizadas com objetivo de viabilizar recursos financeiros, físicos e humanos para os projetos. Apesar dos recursos escassos e poucos incentivos à inovação, o Sargento Ciriaco e seus comandados se superaram para proporcionar resultados de integração e segurança no bairro de Vila Formosa, através de diversos projetos e ações apresentados neste trabalho. A base apresenta-se como um case de sucesso dentro da corporação, que além de atingir a integração proposta, interagiu com muita dinâmica e criatividade com a sociedade. Os resultados obtidos apresentam-se através da redução do número de delitos na região e da constatação de um sentimento diferente da população acerca do papel da polícia como um parceiro da comunidade. Após a apresentação do caso, seguem notas de ensino para aplicação do caso em sala de aula. A experiência relatada foi uma das premiadas na categoria inovação pela 7 ạ edição do Prêmio Mário Covas (2010-2011), realizado pela Secretaria Estadual de Gestão Públicas em parceria com a Fundação do Desenvolvimento Administrativo (FUNDAP) e a Fundação Mário Covas. O objetivo do prêmio é reconhecer e premiar iniciativas de excelência ou inovação no setor público estadual paulista em diversas categorias.

Palavras-chave: policiamento comunitário, Vila Formosa, caso para 
ensino, Prêmio Mário Covas, inovação.

Abstract

Resumen
A teaching case is a description of organizational daily situations with objective of developing skills for problems solution. This case study for teaching is described on the approach of Sergeant Ciriaco, commander of the base. Since 2007, the Military Police Base from Vila Formosa, located in east zone of Sao Paulo city, is part of the community police program. In August 2008, at the beginning of Sergeant Ciriaco management cycle, the philosophy of community integration was adopted. Partnerships with community police from Japan, local traders and other government organizations were established to obtain financial support, human resources and infrastructure for the project. Even with scarce resources and low level of incentives towards innovation, Sergeant Ciriaco and his commanded overcame several limitations to provide results in neighborhood integration and security on Vila Formosa, through a number of projects and actions presented in this paper. The base is a successful case in the police corporation, which, beyond reaching the proposed integration, interacted dynamically and creatively with the society. The results obtained were translated into reduction of the number of crimes in the region and observation of different perceptions among the population regarding the role of the police as a societal partner. After the case study presentation, some teaching notes for application in classroom are provided. The experience was awarded in the category innovation at the $7^{\text {th }}$ Edition of the Mário Covas award (2010-2011), conducted by the State Secretary of Public Management in collaboration with the Foundation of Administrative Development (FUNDAP) and the Mário Covas Foundation. The objective of the award is to acknowledge and award excellence initiatives in the state of São Paulo public sector in several categories.

Keywords: community policing, Vila Formosa, case-based teaching, Mário Covas Award, innovation.

Un caso para la enseñanza es una cuenta de situaciones de la vida de la organización, con el fin de desarrollar habilidades de resolución de problemas. Este caso para la enseñanza es contada de la perspectiva del sargento Ciriaco, comandante de la base. Desde 2007, La base Militar de Policía de Vila Formosa, ubicada en la zona este de São Paulo, es parte del programa de policía comunitaria. En agosto de 2008, en el manejo inicial del sargento Ciriaco, adoptó la filosofía de la integración con la comunidad. Las asociaciones con la policía comunitaria del Japón, los comerciantes locales, y otras agencias gubernamentales se llevaron a cabo con el objetivo de que los recursos financieros, físicos y humanos para los proyectos. A pesar de los escasos recursos y pocos incentivos para la innovación, el sargento Ciriaco y sus hombres fueron superados para proporcionar resultados de la integración y la seguridad en el distrito de Vila Formosa, a través de diversos proyectos y actividades que se presentan en este documento. La base se presenta como un caso de éxito dentro de la corporación, que además de lograr la integración propuesta, interactuaron con la sociedad de manera muy dinámica y creativa. Los resultados obtenidos a través de la reducción de la delincuencia en la zona y encontrar un sentimiento diferente acerca de la población de la función policial como un socio de la comunidad. Después de presentar el caso, siguen las notas de enseñanza para su aplicación en el aula. La experiencia reportada ha sido uno de los premios en la categoría innovación de la 7 a edición de la Silla Mário Covas (2010-2011), llevado a cabo por el Departamento de Gestión Pública, en 
colaboración con la Fundación de Desarrollo Administrativo (FUNDAP) y Fundación Mário Covas. El objetivo del Premio es reconocer y premiar la excelencia y las iniciativas de innovación en el sector público del estado de São Paulo, en varias categorías.

Palabras-clave: policía comunitaria, Vila Formosa, caso para la enseñanza, Silla Mário Covas, innovación. 


\section{Relato do caso ${ }^{1}$}

Ao final de mais um expediente de trabalho no policiamento ostensivo da Polícia Militar do Estado de São Paulo (PM) no bairro de Vila Formosa na cidade de São Paulo, o Sargento Ciriaco recebeu de seus superiores o maior desafio de sua carreira profissional: ser o comandante da Base Comunitária de Segurança de Vila Formosa.

Sem nunca ter tido contato com o que era policiamento comunitário, em agosto de 2009 o Sargento e sua equipe começaram a transformar a atuação da PM no bairro da zona leste da cidade através da integração com a comunidade como filosofia de trabalho.

O que nos anos 1960 era um ponto de ônibus, na Praça Sampaio Vidal se tornou nos anos 1980 um posto da PM. O posto era ocupado por um efetivo de dois policias por turno, que não podiam sair do local para realizarem ronda ostensiva.

No final de 2007 o posto se tornou uma Base Comunitária, que tinha o objetivo de aproximar a relação entre a PM e os cidadãos, alterando a visão da população sobre a PM como braço da ditadura e aumentar o policiamento na região.

Atualmente existem cerca de 250 bases comunitárias no Estado de São Paulo. Desse montante, somente cerca de 60 bases - chamadas de bases-piloto efetivamente exercem projetos com a comunidade da respectiva região.

Até a gestão Ciriaco, a praça onde está localizada a base era ocupada por moradores de rua sem ocupação e palco de constantes roubos aos idosos na saída dos bancos. Em volta da praça existem muitos bancos e a região, de classe média, tem muitos moradores acima dos 60 anos.

Pela base era realizada também a de campanha de doação de roupas, em que eram arrecadadas cerca de 500 peças por ano (uma caixa era deixada na frente da base e uma faixa era colocada nos postes para divulgação).

Os indicadores de criminalidade na área do posto (anos de 2005 e 2006, referentes à gestão anterior à do Sargento Ciriaco) e da base (anos de 2007 e 2008, depois do início do programa em 06 de junho de 2007) são apresentados a seguir (Tabela 1), assim como o número de atividades do posto (até 2007) e da base (a partir de 2007) (Tabela 2).

${ }^{1}$ Baseado na entrevista com o Sargento Ciriaco, em 18 de novembro de 2011. 
Tabela 1. Indicadores de criminalidade na área da base. São Paulo, 2005-2008.

\begin{tabular}{l|c|c|c|c}
\hline Natureza & 2005 & 2006 & 2007 & 2008 \\
\hline Estupro & 1 & 3 & 1 & 3 \\
\hline Latrocínio & 1 & - & - & - \\
\hline Homicídio doloso & 2 & - & - & 2 \\
\hline Roubos veículos & 112 & 95 & 83 & 61 \\
\hline Roubos de cargas & 1 & - & 1 & 1 \\
\hline Roubo a banco & 3 & 3 & 4 & 4 \\
\hline Roubos outros & 237 & 169 & 138 & 150 \\
\hline Furto veículos & 110 & 175 & 198 & 147 \\
\hline Furto outros & 267 & 357 & 420 & 413 \\
\hline
\end{tabular}

Fonte: Dados fornecidos pela base, tendo como fonte a Secretaria de Segurança Pública do Governo do Estado de São Paulo (2011).

Tabela 2. Número de atividades realizadas por ano. São Paulo, 2005-2008.

\begin{tabular}{l|c|c|c|c}
\hline Atividades & 2005 & 2006 & 2007 & 2008 \\
\hline Prisões em flagrante & - & 1 & 1 & - \\
\hline Informações & $\mathrm{n} / \mathrm{d}$ & $\mathrm{n} / \mathrm{d}$ & $\mathrm{n} / \mathrm{d}$ & $\mathrm{n} / \mathrm{d}$ \\
\hline Procurados capturados & - & - & - & - \\
\hline Armas de fogo apreendidas & - & 1 & - & - \\
\hline Entorpecentes apreendidos (Kg.) & - & - & - & - \\
\hline Visitas comunitárias & $\mathrm{n} / \mathrm{d}$ & $\mathrm{n} / \mathrm{d}$ & $\mathrm{n} / \mathrm{d}$ & $\mathrm{n} / \mathrm{d}$ \\
\hline Pessoas abordadas & 1.115 & 1.203 & 1.307 & 1.450 \\
\hline Abordagens a veículos & 1.250 & 1.370 & 1.403 & 1.580 \\
\hline BOPM/TC & 110 & 107 & 120 & 168 \\
\hline Autos de infração & - & - & - & - \\
\hline CRR & - & - & - & - \\
\hline Elogios da comunidade & $\mathrm{n} / \mathrm{d}$ & $\mathrm{n} / \mathrm{d}$ & $\mathrm{n} / \mathrm{d}$ & $\mathrm{n} / \mathrm{d}$ \\
\hline Solicitações & $\mathrm{n} / \mathrm{d}$ & $\mathrm{n} / \mathrm{d}$ & $\mathrm{n} / \mathrm{d}$ & $\mathrm{n} / \mathrm{d}$ \\
\hline Flagrantes de ato infracional & - & - & 1 & - \\
\hline Crianças/adolescentes apreendidos & - & - & 1 & - \\
\hline Ações sociais desenvolvidas & - & - & 4 & 4 \\
\hline Palestras realizadas & - & - & - & - \\
\hline Projetos sociais & - & - & 4 & 4 \\
\hline RAllA & - & - & - & - \\
\hline
\end{tabular}

Fonte: Dados produzidos e fornecidos pela base (2011).

\section{A integração como filosofia de trabalho}

O Sargento Ciriaco, que sempre havia atuado no policiamento ostensivo da corporação, foi escalado para assumir a base em meados de 2009. Formado em Gestão de Segurança, o Sargento Ciriaco utilizou suas habilidades neste campo do conhecimento para selecionar os policiais que, ao seu modo de ver, tinham mais habilidades para lidar com as questões sociais dos projetos comunitários que seriam implementados. 
O Sargento Ciriaco teve autonomia na gestão de pessoas e a possibilidade de contar com um efetivo total de dezesseis policias militares disponíveis na base (são quatro equipes de quatro policiais, em turnos de 12 horas por 36 horas, sendo que dois policiais ficam em permanência e dois fazem o policiamento comunitário - visitas e policiamento).

Dessa forma, alguns escolhidos foram o Cabo Ricardo, mestre na área de meioambiente, a Soldado Andrade, que apresenta grande facilidade de interlocução com as pessoas da comunidade, e o Cabo Brasaroto, formado em assistência social, que compõem o efetivo e a base (Figura 1).

Figura 1. Efetivo e Base comunitária de Vila Formosa. São Paulo, 2011.
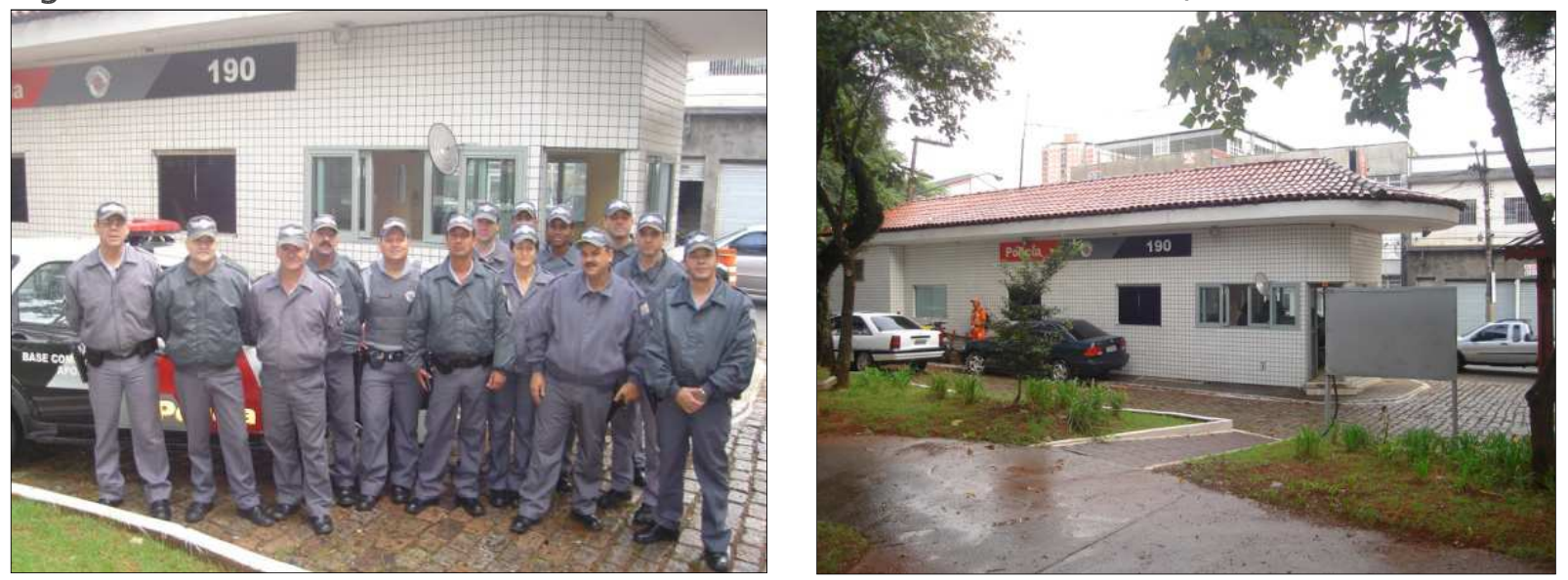

Fonte: Imagens fornecidas pela base (2011).

As parcerias: Cooperação técnica Brasil-Japão e a comunidade

A Base Comunitária de Segurança Vila Formosa, desde seu início no final de 2007, está incluída no Projeto de Cooperação Técnica Brasil-Japão, coordenado pela Agência Internacional de Cooperação do Japão (JICA), em que os policias utilizam o modelo Koban (modelo de policiamento comunitário japonês, adotado em diversos países do mundo) adaptado à realidade brasileira. O Japão possui mais de cento e trinta anos de experiência em polícia comunitária.

Em abril de 2002, existiam 6,5 mil Koban e 8,1 mil Chuzaisho, um para cada jurisdição de cada comunidade. Havia, também, 84 mil policiais nas atividades comunitárias em todo o Japão, correspondentes a cerca de $40 \%$ de toda a força policial japonesa. (...) 'Descobrimos que precisávamos fazer registros das visitas realizadas pelos policiais que atuam nas bases comunitárias e elas deveriam ser mais constantes, para que o nosso profissional ficasse conhecido pela comunidade e a população visse mais de perto o que é o trabalho policial', explica o tenente-coronel PM Luiz de 
Castro Junior, chefe do Estado-Maior do Comando de Policiamento da Capital e coordenador do Projeto de Cooperação Técnica Brasil-japão. (Zanelli 2007).

Além disso, duas das exigências da cooperação são de que a viatura fique em uma área coberta e que informações sejam disponibilizadas à comunidade através de um mural afixado na frente da Base Comunitária de Segurança Vila Formosa (Figura 2).

Figura 2. Cobertura para viatura e quadro informativo. São Paulo, 2011.
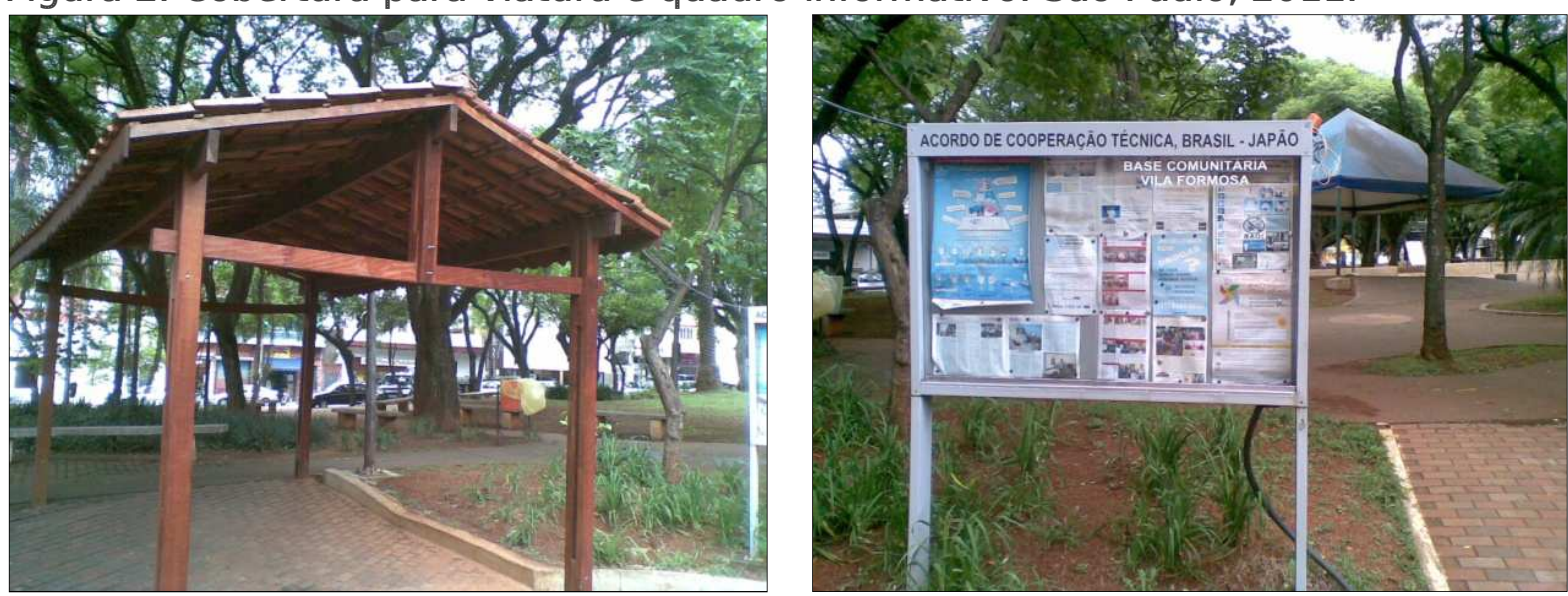

Fonte: Imagens fornecidas pela base (2011).

Mesmo com essas parcerias, o Sargento Ciriaco enfrentou diversos problemas para conseguir recursos, tanto para manter os projetos descritos abaixo, quanto para a manutenção da própria base. A Secretaria de Segurança Pública quase não fornece recursos, exceto os de materiais de escritório e de limpeza.

Para realizar a manutenção da base, bem como dar continuidade aos projetos citados, os recursos são limitados. Contudo, a boa vontade dos policiais supera as dificuldades e compensa a falta de recursos. A saída encontrada para esses problemas foi, prioritariamente, através da parceria com comerciantes locais.

Para a pintura da base, por exemplo, os comerciantes doaram alguns materiais e a tinta foi conseguida com a PM. A parceria com a comunidade, bem como as instituições locais foram primordiais para melhoria das instalações e obtenção de materiais que faltavam para a execução dos projetos e ações.

A parceria permitiu que a base realizasse essas adaptações, comprasse computadores e alugasse equipamentos e suprimentos de impressão. Também possibilitou aos policiais de ambos os países que realizassem intercâmbios para troca de experiências. 


\section{Ações desenvolvidas}

\section{Projeto Hora}

A Praça Sampaio Vidal, local em onde está implantada a base comunitária da Vila Formosa, tinha como característica a presença frequente de moradores de rua sem ocupação, que passavam o dia consumindo bebidas alcoólicas e praticando pequenos delitos. Isto incomodava os moradores e comerciantes do entorno, que se sentiam suscetíveis a essas práticas criminosas.

As constantes reclamações recebidas pelo Sargento Ciriaco o fizeram pensar em uma solução. Aproveitando-se do vasto conhecimento em meio-ambiente do Cabo Ricardo e da disponibilidade de um espaço físico conseguido através de uma parceria com as irmãs da Obra Assistencial São José - situada a poucas quadras da base -, foi criado um projeto voltado ao cultivo de hortaliças, através de uma parceria entre a Base e a instituição.

Nessa atividade, os moradores de rua são responsáveis pelo cultivo das hortaliças, enquanto a Soldado Andrade coordena e oferece todo o suporte técnico para a realização do plantio. Todo o cultivado é destinado a Obra Assistencial. As irmãs colocaram como condição de participação no projeto a obrigatoriedade de seus participantes estarem banhados.

Essa foi uma das formas encontradas para recuperá-los na sociedade. Alguns deles conseguiram arrumar emprego e até mesmo uma família. Outros não aceitaram a condição imposta pelas irmãs e não participaram do projeto. Alguns adolescentes e idosos que frequentam a Praça Sampaio Vidal disseram que a condição do local melhorou e os moradores que ali estão não incomodam mais as pessoas.

\section{Doação de roupas}

No início da base, a coleta de roupas se restringia a um posto de entrega na frente da base e algumas faixas espalhadas pela redondeza como forma de divulgação da campanha. Como já informado acima, somente cerca de 500 peças eram recolhidas anualmente.

O Sargento Ciriaco e sua equipe alteraram a atividade de coleta de roupas, visando um aumento do número de peças doadas pela população. O projeto, desenvolvido pelos policiais da base, consiste em uma arrecadação intensiva pelos condomínios prediais da região da Vila Formosa, cerca de noventa edifícios. 
Primeiramente, os policiais coletam caixas de papelão junto aos comerciantes do entorno da base comunitária. Posteriormente, essas caixas são levadas aos prédios pela viatura. Os policiais ficam encarregados de conversar com os porteiros e de distribuir panfletos sobre a campanha de doação de roupas.

Quando as caixas de papelão estão cheias de roupas, os porteiros comunicam os policiais, que passam recolhendo o material. A base recebe constantes ligações dos porteiros a fim de que sejam retirados os materiais doados pelos moradores.

Com isso, o número saltou para aproximadamente dez mil peças de roupas arrecadadas anualmente. O montante de roupas arrecadadas foi distribuído entre três instituições. A maior parte foi para o fundo de solidariedade estadual, outra parte para a Obra Assistencial São José, para serem repassadas aos moradores de rua, e parte das peças infantis foram repassadas ao abrigo Nosso Lar II.

\section{Projeto Saque Seguro}

Este projeto surgiu a partir da observação dos policiais de que havia um alto índice de roubos, especialmente em "saída de banco", favorecidos principalmente pela desatenção das pessoas após as operações bancárias realizadas ou mesmo no trato com o dinheiro na saída das agências.

Dessa forma, os policiais da base tomaram a iniciativa de propor uma atividade de interação com o público que utiliza as agências da redondeza, a fim de diminuir essas ocorrências. O público-alvo dessa atividade interativa é principalmente o idoso, afinal a vulnerabilidade deste grupo acaba atraindo os infratores.

O papel do efetivo da base comunitária é orientar as pessoas sobre os procedimentos considerados seguros que devem ser seguidos pela população ao utilizarem os serviços bancários. Os policias visitam agências e orientam seus frequentadores.

As principais instruções passadas são: não sacar quantias elevadas que, por ventura, poderiam chamar a atenção de infratores, evitar o manuseio com o dinheiro em espécie logo após a saída da agência e prestar atenção nas pessoas que estão circulando próximas à agência. O Sargento afirma que os roubos de "saída de banco" têm diminuído.

\section{Projeto Idosos}

O bairro de Vila Formosa possui muitos moradores acima dos 60 anos de idade. Essa população reiteradas vezes tem dificuldade para desenvolver suas 
atividades diárias, seja pela dificuldade física de locomoção, falta de acompanhante ou meio de transporte disponível.

Além disso, outras questões relevantes são o abandono familiar aos idosos ocorrendo, inclusive, roubo de aposentadorias e de pensões pelos entes mais jovens - e o desconhecimento do Estatuto do Idoso pelos próprios cidadãos da melhor idade. Em meio a isso, os idosos moradores da região, muitas vezes, ficam carentes por afeto - uma companhia para suas atividades diárias ou mesmo um bate-papo - e indefesos - por não saberem quais são seus direitos.

A vulnerabilidade do idoso e o descaso de alguns familiares levou a equipe da Base Comunitária a propor um projeto que ajudasse essa população na Vila Formosa.

No primeiro eixo de ação é realizado um acompanhamento dos idosos em situações de abandono e vulneráveis - como em saídas de bancos -, bem como, orientar essas pessoas a transitar pelas ruas e avenidas movimentadas evitando perigos como furtos e atropelamentos. Basta o idoso se cadastrar na base para que visitas comunitárias sejam realizadas em sua residência pelas guarnições. Nessa atividade, o Sargento Ciriaco é quem escolhe quais policiais estarão em contato direto com os idosos, de acordo com o perfil dos seus comandados.

O segundo eixo de ação realizado pela base é uma parceria com a obra Assistencial São josé, que realiza oficinas de artesanato com idosos. A base apoia e faz o intermédio com comerciantes locais para conseguir material para as oficinas e com uma fábrica de plástico, material utilizado como matéria-prima na confecção de souvenires. O espaço físico das oficinas é utilizado para que sejam passadas noções de segurança aos idosos e para cadastrar os interessados em receber visitar comunitárias.

O terceiro eixo de ação do projeto consiste em palestras sobre o Estatuto do Idoso, especificamente sobre os direitos legais dos quais os idosos da Vila Formosa desconhecem. Os policiais coordenadores do projeto estudaram a fundo - Estatuto, de forma a passar o maior número de informações aos idosos. Um policial bastante envolvido no projeto é o Cabo Brassaroto, formado em assistência social. Essas informações geralmente são passadas nos atendimentos que a Unidade Básica de Saúde (UBS) do bairro realiza com os idosos, o que gerou uma parceria entre os envolvidos.

A percepção dos policiais que participam desse tipo de atividade é a de que os idosos se sentem muito agraciados com toda a assistência proferida pelos profissionais da base comunitária e que alguns deles ficam entristecidos ao lembrar-se das agressões ou furtos cometidos por seus parentes. Mesmo assim, a maioria opta por não denunciar seus familiares pelo sentimento negativo que isso gera. 


\section{Projeto Conscientização Ambiental}

Uma importante ação realizada com os estudantes das escolas do entorno são orientações sobre educação ambiental na organização do terceiro setor SOTER, através de uma parceria.

O Cabo Ricardo, por ter conhecimento na área, é quem realiza a ação, como uma palestra sobre mudanças climáticas realizada na Escola Estadual Gastão Strang. Complementar a isso, foram implantados, na área externa da base, um coletor de óleo e um coletor de materiais recicláveis (Figura 3).

Figura 3. Palestra sobre mudanças climáticas e coletor de óleo. São Paulo, 2011.
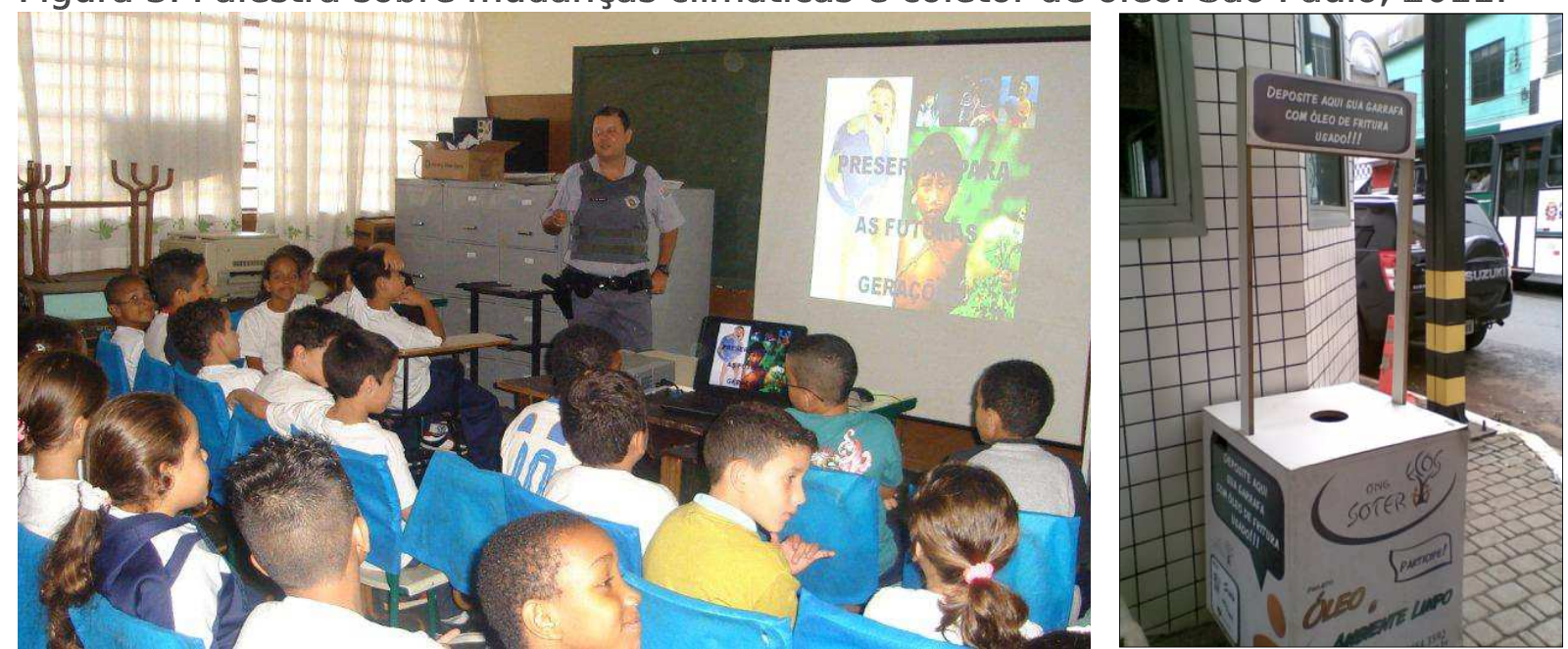

Fonte: Imagens fornecidas pela base (2011).

Além disso, as crianças recebem orientações comportamentais. Certo dia, os policiais da base observaram uma aluna de uma escola particular do bairro - cuja mensalidade do Ensino Fundamental ultrapassa os mil reais - passar pela Praça Sampaio Vidal ostentando seu aparelho de celular.

A partir disso, surgiu a ideia de ir às escolas da região, tanto a pública como as privadas, para falar com os estudantes. Além de passarem orientações quanto a prevenção de roubos e furtos, os policiais buscaram aproximar a PM dos jovens, como forma de melhorar a imagem da corporação perante a comunidade.

O envolvimento dos PMs com os estudantes levou a Soldado Andrade a participar de uma peça de teatro organizada por estudantes de uma escola atendida pela base. 


\section{Informativo}

"Base comunitária Vila Formosa: Destaque internacional" é o título de uma das notícias do Informativo. Em seu quinto ano, esse meio é a principal forma encontrada para a comunicação entre os policias e a comunidade, com o objetivo de deixar a população a par das ações que estão acontecendo.

Além de ter uma tiragem de seis mil exemplares que atende boa parte da comunidade, o informativo é enviado por e-mail desde 2010 e exposto no quadro de avisos da base (Figura 2).

Em duas páginas impressas em colorido no papel fotográfico por uma gráfica parceira da base, o informativo é divulgado mensalmente na comunidade. A contrapartida para a gráfica é divulgar seu logotipo e dados no rodapé de cada edição. Além do periódico, também são divulgadas cartilhas contendo dicas de segurança para a população.

\section{Guardadores de carro}

O grande número de estabelecimentos comerciais que estão em volta da Praça Sampaio Vidal faz com que o fluxo de pessoas durante o dia seja intenso. Dessa forma, as vagas para automóveis ficam ocupadas constantemente e isso abre margem para que os flanelinhas ${ }^{2}$ atuem na região.

No início da gestão do Sargento Ciriaco, várias ocorrências de motoristas insatisfeitos com o tratamento proferido pelos flanelinhas começaram a ocorrer. Os motoristas alegavam que os guardadores de carros os pressionavam a dar determinada quantia de dinheiro em troca da suposta "segurança".

Certo dia uma mulher foi à Base Vila Formosa e disse que um flanelinha havia ameaçado-a. Questionada se desejava dar queixa, não aceitou - apenas queria que os policiais dessem um susto no sujeito. Nada foi feito em um primeiro momento.

A solução encontrada pelo Sargento para colocar um fim nesse problema foi primeiramente chamar todos os guardadores de carro na base comunitária com o objetivo de cadastrá-los e informá-los sobre os constantes problemas que estavam causando - alguns já tinham passagem pela polícia e decidiram abandonar o local.

${ }^{2}$ Guardadores de carros, geralmente encontrados nos grandes centros urbanos. 
Posteriormente, os policiais solicitaram aos flanelinhas que usassem um colete de trabalho que cobrisse a parte superior do corpo por inteiro. Ficou acordado que os guardadores de carros iriam continuar exercendo sua atividade no local desde que respeitassem os motoristas e usassem o colete.

Tanto os policiais como os guardadores de carros disseram que, após essa decisão, a situação se normalizou e quase nenhum novo incidente foi contabilizado. "Eles não mexem com nóis (sic), deixam nóis (sic) trabalhar em paz, e nóis (sic) não mexemos com eles. Fica cada um no seu canto.", foi o que disse um guardador de carro ao ser questionado sobre a relação dos guardadores com a Base.

\section{Resultados}

A partir das ações empreendidas, buscou-se analisar os indicadores de criminalidade na área do posto (até 2007) e da base (a partir de 2007), assim como o número de atividades do posto (até 2007) e da base (a partir de 2007), apresentando-se dados atualizados para efeito de comparação ates e após a gestão do Sargento Ciriaco (Tabelas 3 e 4).

Tabela 3. Indicadores de criminalidade na área da base. São Paulo, 2005-2011.

\begin{tabular}{l|c|c|c|c|c|c|c}
\hline Natureza & 2005 & 2006 & 2007 & 2008 & 2009 & 2010 & $2011 *$ \\
\hline Estupro & 1 & 3 & 1 & 3 & 1 & 3 & - \\
\hline Latrocínio & 1 & - & - & - & - & 1 & - \\
\hline Homicídio doloso & 2 & - & - & 2 & - & 1 & - \\
\hline Roubos veículos & 112 & 95 & 83 & 61 & 81 & 84 & 31 \\
\hline Roubos de cargas & 1 & - & 1 & 1 & 1 & - & 1 \\
\hline Roubo a banco & 3 & 3 & 4 & 4 & 4 & 1 & - \\
\hline Roubos outros & 237 & 169 & 138 & 150 & 232 & 178 & 89 \\
\hline Furto veículos & 110 & 175 & 198 & 147 & 75 & 95 & 41 \\
\hline Furto outros & 267 & 357 & 420 & 413 & 332 & 224 & 144 \\
\hline
\end{tabular}

Fonte: Dados produzidos e fornecidos pela base (2011).

(*) Até outubro de 2011. 
Tabela 4. Número de atividades realizadas no ano. São Paulo, 2005-2011.

\begin{tabular}{l|c|c|c|c|c|c|c}
\hline Atividades & 2005 & 2006 & 2007 & 2008 & 2009 & 2010 & 201 * $^{*}$ \\
\hline Prisões em flagrante & - & 1 & 1 & - & 12 & 12 & 8 \\
\hline Informações & $\mathrm{n} / \mathrm{d}$ & $\mathrm{n} / \mathrm{d}$ & $\mathrm{n} / \mathrm{d}$ & $\mathrm{n} / \mathrm{d}$ & 6.123 & 7.191 & 6.956 \\
\hline Procurados capturados & - & - & - & - & 1 & 3 & 2 \\
\hline Armas de fogo apreendidas & - & 1 & - & - & - & 1 & 3 \\
\hline $\begin{array}{l}\text { Entorpecentes apreendidos } \\
\text { (kg) }\end{array}$ & - & - & - & - & 3 & 2 & - \\
\hline Visitas comunitárias & $\mathrm{n} / \mathrm{d}$ & $\mathrm{n} / \mathrm{d}$ & $\mathrm{n} / \mathrm{d}$ & $\mathrm{n} / \mathrm{d}$ & 269 & 647 & 640 \\
\hline Pessoas abordadas & 1.115 & 1.203 & 1.307 & 1.450 & 5.898 & 4.041 & 6.366 \\
\hline Abordagens a veículos & 1.250 & 1.370 & 1.403 & 1.580 & 4.140 & 3.861 & 5.150 \\
\hline BOPM/TC & 110 & 107 & 120 & 168 & 240 & 296 & 207 \\
\hline Autos de infração & - & - & - & - & 339 & 265 & 235 \\
\hline CRR & - & - & - & - & 32 & 19 & 47 \\
\hline Elogios da comunidade & $\mathrm{n} / \mathrm{d}$ & $\mathrm{n} / \mathrm{d}$ & $\mathrm{n} / \mathrm{d}$ & $\mathrm{n} / \mathrm{d}$ & 255 & 353 & 222 \\
\hline Solicitações & $\mathrm{n} / \mathrm{d}$ & $\mathrm{n} / \mathrm{d}$ & $\mathrm{n} / \mathrm{d}$ & $\mathrm{n} / \mathrm{d}$ & 273 & 373 & 724 \\
\hline Flagrantes de ato infracional & - & - & 1 & - & - & - & - \\
\hline $\begin{array}{l}\text { Crianças/adolescentes } \\
\text { apreendidos }\end{array}$ & - & - & 1 & - & - & - & - \\
\hline Ações sociais desenvolvidas & - & - & 4 & 4 & 13 & 23 & 23 \\
\hline Palestras realizadas & - & - & - & - & 16 & 39 & 60 \\
\hline Projetos sociais & - & - & 4 & 4 & 4 & 5 & 6 \\
\hline RAllA & - & - & - & - & - & 2 & 2 \\
\hline
\end{tabular}

Fonte: Dados produzidos e fornecidos pela base (2011).

(*) Até outubro de 2011.

A evolução dos índices de produtividade da base destaca o aumento das visitas comunitárias (Gráfico 1 ).

Gráfico 1. Índice de produtividade da Base Comunitária de Segurança de Vila Formosa. São Paulo, 2011.

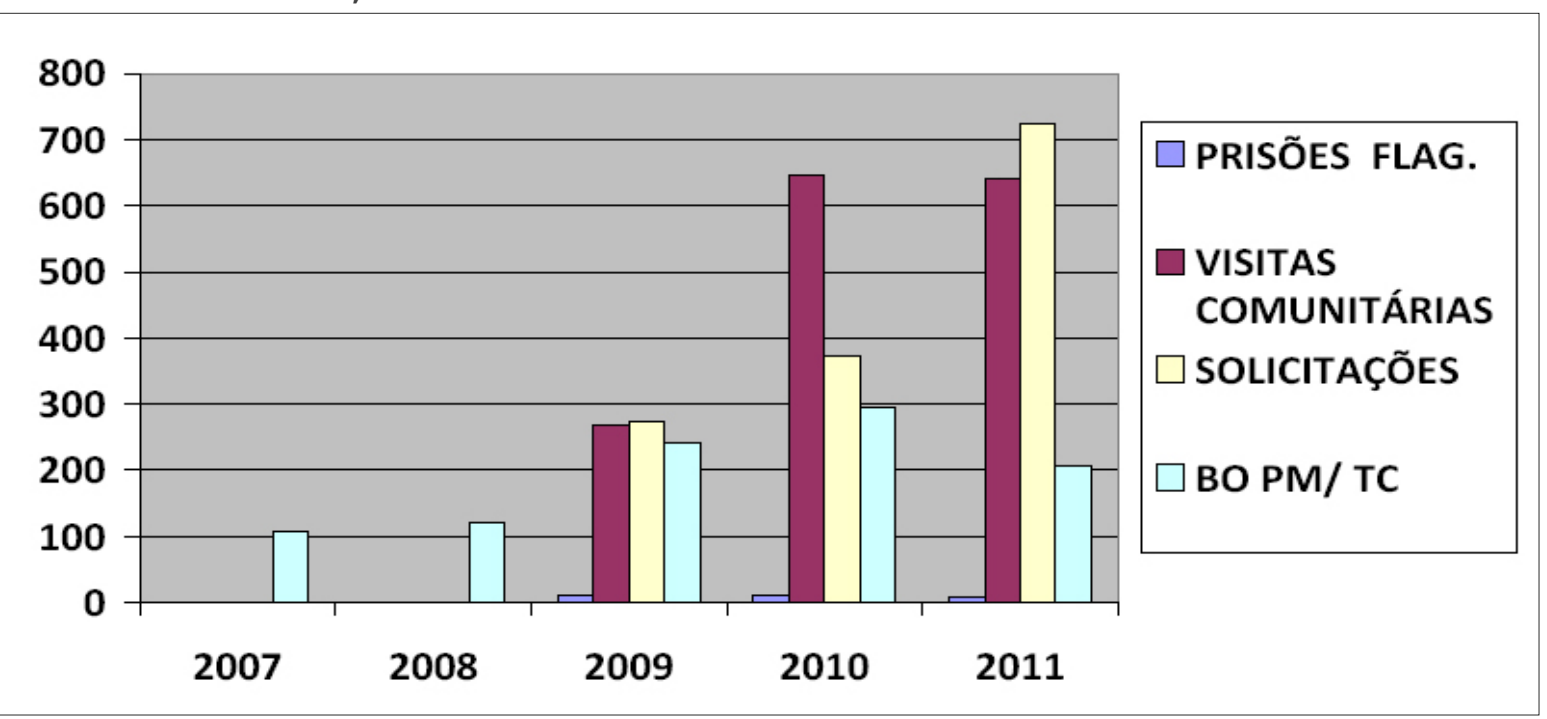

Fonte: Dados produzidos e fornecidos pela base (2011). 
Atual desafio: O hospital abandonado

Mesmo com a melhora dos indicadores, os problemas ainda existem. Nas proximidades da base comunitária da Vila Formosa há um hospital particular abandonado, desde que foi abandonado em 2006.

O descaso do poder público em tomar providências para com aquela edificação acabou por causar um processo de ocupação irregular de moradores de rua, usuários de drogas e álcool.

No entanto, o problema não se restringe a ocupação irregular do prédio. Esses indivíduos frequentam o perímetro urbano próximo a base e consumem drogas e álcool.

Os policiais comunitários, incomodados com esta situação, tentaram por inúmeras vezes estabelecer um contato a fim de que esses indivíduos não mais consumissem produtos ilícitos. Além disso, uma ficha de cadastro foi preenchida pelos moradores de rua. Porém, a medida pareceu ter sido em vão e esses indivíduos continuam a frequentar a região.

\section{Notas de ensino}

Na segunda parte do artigo, são apresentadas as notas de ensino dirigidas ao docente para aplicação deste caso em sala de aula, que incluem: a) fonte de obtenção dos dados/informações; b) objetivos de ensino-aprendizagem; c) recomendações para aplicação do caso; e d) questões para reflexão e discussão a partir do caso.

\section{Fonte de obtenção dos dados/informações}

As informações registradas no caso são reais, tanto os resultados, quanto o nome dos personagens. Foram obtidas através da apresentação do case pelo Sargento Ciriaco e por uma entrevista realizada com o mesmo - que prontamente autorizou a produção e divulgação das informações desde que respeitassem a integridade da corporação - em uma visita realizada pelos autores à Base Comunitária de Segurança da Vila Formosa.

Em seguida, foram realizados ajustes no texto de acordo com as solicitações do Sargento. Para tornar a leitura mais interessante ao leitor, optou-se por uma escrita pouco formal, embora técnica para manter o rigor científico. 


\section{Objetivos de ensino-aprendizagem}

Este caso para ensino é recomendado para alunos do curso de graduação em Gestão de Políticas Públicas, Políticas Públicas, Administração Pública ou similares, em disciplinas que abordem a relação entre princípios legais da administração pública e a prática, a formulação e a implementação de políticas públicas, projetos no setor público e inovações no setor público advindas da iniciativa de determinadas repartições públicas.

Busca-se indagar sobre a relação entre o papel dos burocratas de nível de rua na formatação da política pública (Lipsky 1980, Meyers e Vorsanger 2010) as ideias/premissas presentes na constituição de um projeto como o caso da Base Comunitária da Vila Formosa e os desafios que um gestor deve lidar nas diversas áreas de gestão (planejamento, recursos humanos, recursos financeiros, etc.).

Espera-se que o aluno se coloque no papel de gestor, discutindo a forma com que as decisões foram tomadas diante das situações de conflito apresentadas no caso.

\section{Recomendações para aplicação do caso}

Em uma aula de uma hora e 45 minutos, sugere-se a seguinte aplicação:

1. Leitura do caso e da bibliografia citada.

a. Individual (prévia, antes da aula);

b. Compartilhada, em grupo de cinco alunos, apontando as principais situações problema e as decisões tomadas pelo gestor, assim como os constrangimentos apresentados ( 15 minutos).

2. Apresentação das questões pelo professor (10 minutos).

3. Discussão em grupo e posicionamento final do grupo acerca das decisões tomadas pelo gestor diante dos acontecimentos (30 minutos).

4. Exposição do posicionamento de cada grupo para a turma com feedback de outros grupos e o professor acerca das questões para reflexão e discussão (50 minutos).

Questões para reflexão e discussão a partir do caso

1. Tomando o Sargento Ciriaco e seus comandados como burocratas de nível de rua e a visão deles sobre os cidadãos, discuta sua influência sobre a política 
de policiamento comunitário e seus efeitos para a comunidade, positivos e negativos, com base no seguinte trecho:

Em alguns estudos esses trabalhadores aparecem como peças frustradas e impotentes em máquinas burocráticas; em outros, como egoístas, cujos mecanismos de enfrentamento distorcem as intenções de políticas dos funcionários eleitos; em outros ainda, como líderes locais heroicos, que traduzem diretrizes de políticas para o benefício de seus clientes (Meyerse Vorsanger 2010:260).

2. De acordo com o Artigo 37 da Constituição Federal de 1988, a administração pública deve se pautar pelo princípio da impessoalidade, entre outros. Esse princípio foi ferido em alguma das ações da base? Alguns cidadãos foram tratados de forma diferente em relação a outros? Poderia ter sido feito de alguma outra forma?

A administração pública direta e indireta de qualquer dos Poderes da União, dos Estados, do Distrito Federal e dos Municípios obedecerá aos princípios de legalidade, impessoalidade, moralidade, publicidade e eficiência e, também, ao seguinte (Brasil 1988).

3. De que formas o comando da base pode minimizar os conflitos (quais e em que áreas de gestão?) decorrentes da contraposição entre o modelo militarizado de polícia e o policiamento comunitário, tomando como base a seguinte afirmação:

É sabido que qualquer tentativa de flexibilização da hierarquia e de autonomização dos agentes de ponta em todos os tipos de instituições, especialmente nas instituições públicas, onde a "mentalidade de casta" em geral é mais arraigada esbarra em resistências iniciais. Não poderia ser diferente numa estrutura militar tradicional como a da PM, que se caracteriza justamente pela atribuição de prestígio hierárquico, pelo controle disciplinar, pela concentração de poder decisório nos escalóes superiores, enfim pelo 'excesso de militarismo'. (Muniz et al. 1997:205).

4. Que ações poderiam ser tomadas pela base, e quais seus limites, para a resolução do problema do hospital abandonado? 


\section{Referências}

Brasil. Constituição da República Federativa do Brasil. Atualizada até a Emenda Constitucional 57, de 18 de dezembro de 2008. São Paulo: Imprensa Oficial do Estado de São Paulo, 2009.

Lipsky M. Street-level bureaucracy: Dilemmas of the individual in public services. New York: Russell Sage Foundation, 1980.

Meyers MK, Vorsanger S. Burocratas de nível de rua e a implementação de políticas públicas. In: Peters B, Pierre J (Orgs.). Administração pública: Coletânea., Brasília: ENAP / São Paulo: Editora UNESP, 2010.

Muniz J, Larvie SP, Musumeci L, Freire B. Resistências e dificuldades de um programa de policiamento comunitário. Tempo social 1997, 9(1): 197-213.

Roesch SMA. Notas sobre a construção de casos para ensino. Casos de ensino em administração. Revista de Administração Contemporânea 2007, 11(2):213234.

Zanelli ML. PM de São Paulo renova convênio técnico com polícia japonesa até 2008. Portal de Notícias do Governo do Estado de São Paulo. Publicada em 17 abr. 2007. Disponível na internet em: http://www.saopaulo.sp.gov.br/spnoticias/lenoticia.php?id=83750 [ Acesso em nov. 2011]. 